\title{
miR-106a contributes to prostate carcinoma progression through PTEN
}

\author{
JI LU ${ }^{1}$, XUPENG MU ${ }^{2}$, QINAN YIN ${ }^{3,4}$ and KEBANG HU ${ }^{1}$ \\ ${ }^{1}$ Department of Urology, The First Hospital, Jilin University, Changchun, Jilin 130021; \\ ${ }^{2}$ Department of Central Laboratory, China-Japan Union Hospital, Jilin University, Changchun, Jilin 130033, P.R. China; \\ ${ }^{3}$ Clinical Center, National Institute of Health, Bethesda, MD 20852, USA; \\ ${ }^{4}$ Department of Gynecology and Obstetrics, China Meitan General Hospital, Beijing 100028, P.R. China
}

Received February 1, 2017; Accepted March 14, 2018

DOI: $10.3892 / \mathrm{ol} .2018 .9697$

\begin{abstract}
Prostate carcinoma is a global health problem and is estimated to be diagnosed in 1.1 million men/year, making this malignancy the second most frequently diagnosed cancer in males worldwide. micro RNAs (miRNAs) are small non-coding RNAs that negatively regulate gene expression at the post-transcriptional level. miRNAs contribute to cancer development and progression, and are expressed differently in normal tissues and cancers. In the present study, the biological function of miR-106a in the human prostate carcinoma and the associated regulatory mechanisms were investigated. miR-106a was significantly upregulated in human prostate cancer tissues when compared with normal tissues $(\mathrm{P}<0.05)$, and the overexpression of miR-106a was identified to promote PC-3 cell growth. Additionally, miRNA-106a inhibition significantly suppressed PC-3 cell growth. Furthermore, it was observed that the phosphatase and tensin homolog (PTEN) expression level was negatively associated with miR-106a expression level, and miRNA-106a directly targeted PTEN in the PC-3 cells. PTEN overexpression has a similar effect on PC-3 cell growth as loss of miR-106a. Taken together, the results of the present study indicate that upregulated miR-106a regulates PC-3 cell proliferation through PTEN. These results suggest that appropriate manipulation of miR-106a may provide a novel strategy in the future treatment of human prostate cancer.
\end{abstract}

\section{Introduction}

Prostate carcinoma is currently one of the most common types of non-cutaneous cancer among males and its incidence

Correspondence to: Dr Kebang Hu, Department of Urology, The First Hospital, Jilin University, 71 Xin-min Avenue, Chaoyang, Changchun, Jilin 130021, P.R. China

E-mail: hu.kebang.MD@gmail.com

Key words: prostate carcinoma, miR-106a, phosphatase and tensin homolog, cell proliferation increases with age. The diagnosis and staging of this cancer has attracted a great deal of public interest. Significant advances in its treatment have been made recently; however, there are limitations regarding the screening tools used for this cancer (1). Therefore, it is imperative to identify novel potential biomarkers for the diagnosis and prevention of the induction and progression of prostate carcinoma.

Biomarkers serve an essential role in the detection and treatment of disease. A biomarker is a characteristic that is capable of being measured in a laboratory/clinical setting, is associated with the pathological process, and has diagnostic and prognostic utility (2). If the disease is diagnosed in the early stages, the therapeutic success rates for patients with prostate carcinoma are substantially improved. Therefore, a successful therapy for this disease depends on the biomarkers for detection of the presence and progression of the disease. However, the current biomarkers for prostate carcinoma are not ideal (3). Previously, microRNAs (miRNAs) have exhibited potential as biomarkers in prostate cancer (4). The aberrant regulation of miRNAs has long been recognized as one of the mechanisms that contribute to numerous types of tumors, including prostate cancer (5). miRNAs are non-coding small RNAs of 19-25 nucleotides in length that regulate mRNA expression primarily by binding to the complementary sequences in the 3'-untranslated region (3'-UTR) (6). miRNAs have been demonstrated to serve essential roles in cancer research including tumor growth, invasion and metastasis (7,8). MiR-26a and miR-26b have been demonstrated to inhibit cell aggressiveness by regulating fucosyltransferase 4 in colorectal cancer (9). In solid tumors, the expression of miRNAs has been identified to be dysregulated and the alternation of miRNA expression is causatively associated with the development of cancer (10). Although much is known about the profiles of miRNAs in numerous tumors and tissues, the function of miRNAs in prostate cancer has not yet been completely elucidated.

The phosphatase and tensin homolog (PTEN) gene was initially identified as a tumor suppressor $(11,12)$. Recently, PTEN has been verified as a functional target of various miRNAs and has served different biological functions in different type of cancers (13). It has been reported that miR-21 regulated growth and metastasis in non-small cell lung cancer cells by targeting PTEN (14). Additionally, miR-32 has been 
identified to promote growth, migration, and invasion via PTEN in colorectal carcinoma cells (15). However, the role of PTEN is not fully understood in prostate carcinoma.

Herein, the present study demonstrates that miR-106a is significantly upregulated in prostate cancer tumors, with functional studies indicating that miR-106a promotes PC-3 cell growth via PTEN. PTEN may potentially be exploited in a therapeutic approach to prostate carcinoma.

\section{Materials and methods}

Cell culture and tumor tissues. The PC- 3 cell line is considered to be a classical human prostate cancer cell line for the study of human prostate cancer (16). The PC-3 cell line was purchased from the American Tissue Culture Collection (ATCC; Manassas, VA, USA) and cultured according to the supplier's recommendations. Cells were cultured in a ATCC-formulated F-12K medium and supplemented with $10 \%$ fetal bovine serum (FBS) (Atlanta Biologicals, Flowery Branch, GA, USA), $100 \mathrm{U} / \mathrm{ml}$ penicillin, and $100 \mathrm{mg} / \mathrm{ml}$ streptomycin (Sigma-Aldrich; Merck KGaA, Darmstadt, Germany) at $37^{\circ} \mathrm{C}$ in a humidified atmosphere with $5 \% \mathrm{CO}_{2}$.

Prostate cancer and noncancerous prostate tissues were obtained from the tissue bank of The First Hospital of Jilin University (Changchun, China). The age in the cancer group ranged between 49 and 80 years with a median age of 69 years. In the noncancerous group, the age ranged between 50 and 76 years, with a median age of 65 years. Tissues were collected between June 2014 and June 2016, and frozen in liquid nitrogen immediately after mincing (cutting into small pieces) on ice and were then stored at $-80^{\circ} \mathrm{C}$ until subsequent analysis. All patients were male. There was no inclusion/exclusion criterion for patient selection in the present study. Written informed consent was acquired from all patients, and ethical approval was obtained from Institutional Review Board of The First Hospital of Jilin University.

Reverse transcription-quantitative polymerase chain reaction $(R T-q P C R)$. Total RNA from tissues and cells were isolated by a TRIzol reagent (Invitrogen; Thermo Fisher Scientific, Inc., Waltham, MA, USA) according to the manufacturer's protocol. Residual RNAs were reverse transcribed into cDNA with M-MLV reverse transcriptase (Thermo Fisher Scientific, Inc.). Briefly, the following components were added to a nuclease-free microcentrifuge tube: Oligo (dT) $(500 \mu \mathrm{g} / \mathrm{ml})$ $(1 \mu \mathrm{l})$, total RNA $(1 \mu \mathrm{g}), 10 \mathrm{mM}$ dNTP mix $(1 \mu \mathrm{l})$ and distilled water to $12 \mu \mathrm{l}$. The mixture was heated to $65^{\circ} \mathrm{C}$ for $5 \mathrm{~min}$ and chilled on ice $\left(0^{\circ} \mathrm{C}\right)$. Subsequently, the $5 \mathrm{X}$ first-strand buffer $(4 \mu \mathrm{l}), 0.1 \mathrm{M}$ DTT $(2 \mu \mathrm{l})$ and distilled water $(1 \mu \mathrm{l})$ were added into the tube. Following a brief centrifugation $(1 \mathrm{~min}$ at $1,000 \mathrm{x} \mathrm{g}$, at room temperature), the mixture was incubated at $37^{\circ} \mathrm{C}$ for $2 \mathrm{~min}$. Following the addition of M-MLV reverse transcriptase $(1 \mu \mathrm{l})$, the mixture was incubated at $37^{\circ} \mathrm{C}$ for $50 \mathrm{~min}$. The reaction was inactivated by heating at $70^{\circ} \mathrm{C}$ for $15 \mathrm{~min}$. All components were purchased from Thermo Fisher Scientific. The residual DNA was removed by DNA-free DNase (Thermo Fisher Scientific, Inc.). For mature miRNA determination in tissues and cells, the TaqMan microRNA assay was performed in accordance with the instruction of the TaqMan microRNA reverse transcription kit (Thermo Fisher Scientific, Inc.).
For specific gene quantitation, RNAs were reverse transcribed into cDNA with M-MLV reverse transcriptase (Gibco; Thermo Fisher Scientific, Inc.). The Taqman RT-qPCR was used for PTEN gene expression analysis. GAPDH was used as a reference gene to normalization (17). All specific Taqman probes are commercially available from Applied Biosystems (Thermo Fisher Scientific, Inc.; PTEN cat no. Hs02621230_s1 and GAPDH cat no. Hs02786624_g1). All assays were performed in triplicate on an ABI 7500 system (Applied Biosystems; Thermo Fisher Scientific, Inc.). The thermocycling conditions were as follows: Hold stage, $95^{\circ} \mathrm{C}$ for $20 \mathrm{sec}$; PCR stage, $95^{\circ} \mathrm{C}$ for $1 \mathrm{sec}, 60^{\circ} \mathrm{C}$ for $20 \mathrm{sec}$ for $1 \mathrm{cycle}$, 40 cycles total. The data are presented as the mean \pm standard error of the mean $(\mathrm{SE})(\mathrm{n}=3)$.

Transfection of microRNA mimic. A total of $50 \mathrm{nM}$ miR-106a mimic or miRNA vector control (miR-con) were reverse transfected in to PC-3 cells by Lipofectamine RNAiMAX (Thermo Fisher Scientific, Inc.) as described by the study protocol of Reid et al (18). miR-106a mimic and miR-con were purchased from Shanghai GenePharma Co., Ltd. (Shanghai, China). The miR-106a mimic sequence was as follows: 5'-GAUGGACGU GACAUUCGUGAAAA-3'. After $48 \mathrm{~h}$ transfection, the cells were available for subsequent assays.

3'-UTR dual luciferase assay. PC-3 cells were seeded in a 96-well plate at a density of $2 \times 10^{4}$ cells/well. The cells were co-transfected with $100 \mathrm{ng}$ miR-106 mimic (Shanghai GenePharma Co., Ltd.) and 10 ng PTEN 3'-UTR luciferase reporter construct (GeneCopoeia, Inc., Rockville, MD, USA) with Lipofectamine 2000 (Invitrogen; Thermo Fisher Scientific, Inc.). The empty vector was used as a control (VC). The dual-luciferase activities were measured after $24 \mathrm{~h}$ in accordance with the instructions of the Duo-Luciferase kit 2.0 (GeneCopoeia, Inc.). Results were normalized by comparison with a Renilla luciferase activity.

miR-106a inhibition. Inhibition of miR-106a expression was performed by a method previously described (19). Briefly, $60 \mathrm{nM}$ antisense inhibitor miR-106a or scrambled control antisense inhibitor (GE Healthcare Dharmacon, Inc., Lafayette, CO, USA) were transfected into PC-3 cells $\left(2 \times 10^{4}\right.$ cells/well) using Lipofectamine 2000 (Invitrogen; Thermo Fisher Scientific, Inc.). Cells were harvested for subsequent experimentation after $48 \mathrm{~h}$ incubation.

PTEN overexpression. For the PTEN overexpression, a PTEN lentiviral system (lenti-PTEN) was used to stably overexpress PTEN in PC-3 cells. Lentiviral control vector (lenti-Con) was used as a negative control. These are commercially available from Applied Biological Materials Inc., (Richmond, Canada). PC-3 cells were seeded into a 24 well plate (at $0.5 \times 10^{5}$ cells/well). The next day, PC-3 cells were infected with lenti-PTEN or lenti-Con at a multiplicity of infection of 10 using polybrene $(8 \mu \mathrm{g} / \mathrm{ml}$; Thermo Fisher Scientific, Inc.) for $24 \mathrm{~h}$. Subsequently, the culture medium was replaced with $1 \mathrm{ml}$ complete medium (ATCC-formulated F-12K medium and supplemented with $10 \%$ FBS, $100 \mathrm{U} / \mathrm{ml}$ penicillin, and $100 \mathrm{mg} / \mathrm{ml}$ streptomycin). The cells were incubated at $37^{\circ} \mathrm{C}$ with $5 \% \mathrm{CO}_{2}$ overnight for subsequent assays. 
Western blotting. Cells were lysed in RIPA Lysis and Extraction buffer (Thermo Fisher Scientific, Inc.), and protein concentrations were determined using a DC Protein Assay kit (Bio-Rad Laboratories, Inc., Hercules, CA, USA). A total of $15 \mu \mathrm{g}$ protein from PC-3 cells were separated using 4-20\% gradient SDS-PAGE (Invitrogen; Thermo Fisher Scientific, Inc.). Afterwards, the gel was electrophoretically transferred onto a polyvinylidene difluoride membrane and the membranes were incubated with the PTEN primary antibody at $4^{\circ} \mathrm{C}$ overnight (cat no. ab31392; 1:500 dilution; Abcam, Cambridge, MA, USA). Secondary antibodies (Goat anti-rabbit antibody conjugated to horseradish peroxidase; cat no. 1662408EDU; 1:1,000 dilution; Bio-Rad Laboratories, Inc.) were added on the next day after washing three times with TBST, 5 min each. After $2 \mathrm{~h}$ incubation at room temperature, the proteins were visualized using enhanced chemiluminescence (SuperSignal $^{\text {TM }}$ West Femto Maximum Sensitivity Substrate; Thermo Fisher Scientific, Inc.) and GAPDH (cat no. ab9485; 1:500 dilution; Abcam) from the same membrane was used as a loading control. All experiments were repeated three times.

Cell proliferation assay. CyQuant assay (CyQUANT ${ }^{\mathrm{TM}}$ Cell Proliferation Assay kit; Thermo Fisher Scientific, Inc.), a fluorescence-based microplate assay, was used to determine cell growth according to the manufacturer's protocol. Briefly, $5 \times 10^{3}$ PC-3 cells/well were seeded in a 96-well tissue culture plate in $100 \mu \mathrm{l}$ media/well. The CyQuant solution was prepared immediately prior to use at indicated time points. Following the removal of media, $100 \mu \mathrm{l}$ of CyQuant solution was added to the wells and incubated in the dark for $45 \mathrm{~min}$ at room temperature. The plate was read at excitation at $497 \mathrm{~nm}$ and emission at $520 \mathrm{~nm}$. Data was presented as the mean $\pm \mathrm{SE}$ of three independent experiments.

Statistical analysis. GraphPad Prism (version 6.07 for Windows; Graphpad Software, Inc., La Jolla, CA, USA) was used to analyze data. Data are presented as means \pm SE. An unpaired Student's t-test was used for comparison between two groups and one-way analysis of variance test followed by Tukey's multiple comparison test was used to compare the significance of differences between the means of multiple groups. IBM SPSS Statistics 21 (IBM Corp., Armonk, NY, USA) was used for statistical analysis. $\mathrm{P}<0.05$ was considered to indicate a statistically significant difference.

\section{Results}

Levels of miR-106a are upregulated in tumor tissues. Of microarray preliminary studies in the screening of miRNAs from tumor tissues (14 cases) versus noncancerous prostate tissues (18 cases), miR-106a was identified to have a 1.8-fold upregulation in prostate tumors, which is considered significant (data not shown). In the present study, mature miR-106a levels in prostatic tumors and normal tissues were compared using RT-qPCR. As shown in Fig. 1, there was a significantly increased expression of miR-106a in tumor samples when compared with normal tissues, suggesting that miR-106a may be responsible for the progression of prostate carcinoma.

miR-106a promotes cell growth in vitro. To decipher the functional effects of miR-106a, a synthetic miR-106a mimic

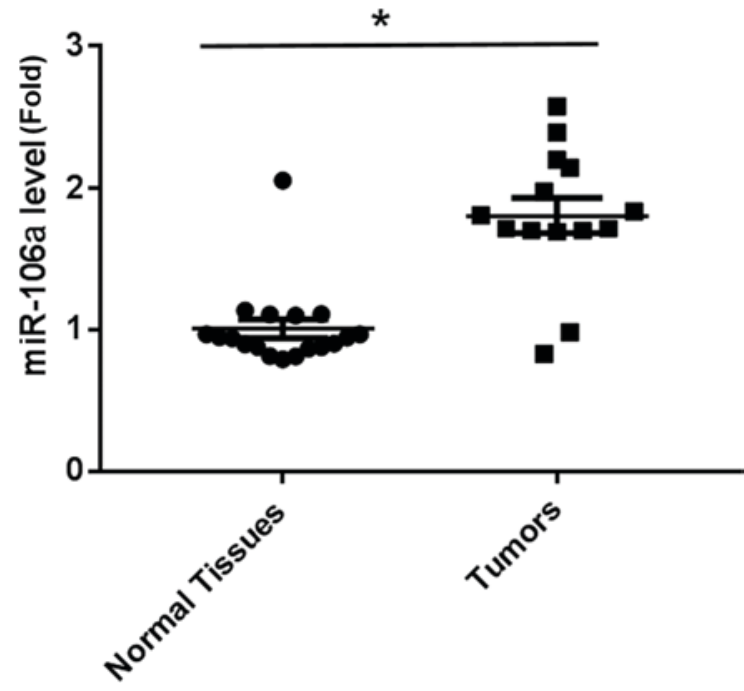

Figure 1. Reverse transcription-quantitative polymerase chain reaction analysis of miR-106a in normal tissues $(n=18)$ and human prostate tumor tissues $(\mathrm{n}=14)$. Data are shown as mean \pm standard error, ${ }^{*} \mathrm{P}<0.05$ vs. normal tissues. miR, microRNA.

was transfected into PC-3 cells, and the miR-106a expression level following transfection was determined to be significantly increased compared with the wild-type and VC control groups (Fig. 2A). As shown in Fig. 2B, the miR-106a mimic significantly promoted cell growth in PC-3 cells compared with a control mimic, which did not affect growth. To further confirm these results, a reverse study was performed to confirm the role of miR-106a in the PC-3 cells following the inhibition of miR-106a. Transfection of miR-106a antisense inhibitor into PC-3 cells produced an $\sim 70 \%$ decrease in miR-106a levels as measured by RT-qPCR compared with the scrambled control (Fig. 2C). As shown in Fig. 2D, the miR-106a inhibitor significantly suppressed PC-3 cell growth, which is in line with the effects observed following overexpression of miR-106 in PC-3 cells. Therefore, the next step was to evaluate the potential mechanisms of miR-106a on cell proliferation.

PTEN expression is repressed by miR-106a. A previous study identified an association between miR-106a and PTEN (20). To determine whether the cell grow th promotive effects observed with miR-106a in PC-3 cells was also associated with the downregulation of PTEN, the expression of PTEN mRNA in tumor and normal tissues was analyzed. PTEN mRNA levels were demonstrated to be significantly decreased in the tumor tissues in comparison with normal tissues (Fig. 3A).

To further confirm this observation, PC-3 cells were co-transfected with the PTEN 3'-UTR luciferase reporter and miR-106a or miR-con. The results revealed that miR-106a significantly repressed the activity of PTEN compared with the miR-con (Fig. 3B).

PTEN overexpression suppressed cell growth in vitro. To assess whether PTEN overexpression caused a similar response in PC-3 cell growth as was caused by miR-106a downregulation, PTEN was stably overexpressed in PC-3 cells. PTEN was overexpressed by lentiviral-PTEN. Lentiviral-PTEN significantly increased the mRNA and 

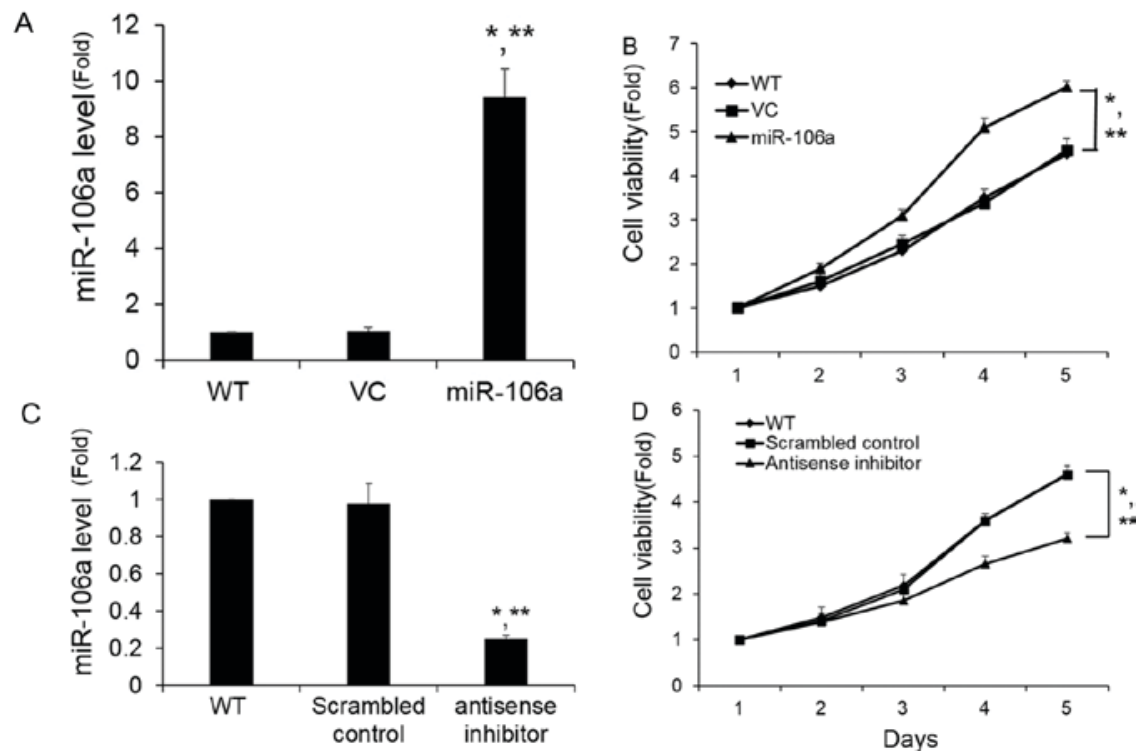

Figure 2. Effect of miR-106a on cell growth of PC-3 cells. (A) PC-3 cells were transfected with miR-106a mimic or VC. miR-106a expression level was determined by RT-qPCR. Data were expressed as the fold change relative to WT cells $(\mathrm{n}=3)$. (B) PC-3 cells were transfected with miR-106a mimic or VC were seeded in a 96-well plate to monitor cell proliferation. Data are expressed as relative fold change compared with day 0. Data was shown as mean $\pm \mathrm{SE}$, ${ }^{*} \mathrm{P}<0.05$ vs. WT $(n=3) ;{ }^{* *} \mathrm{P}<0.05$ vs. VT $(\mathrm{n}=3)$. (C) miR-106a inhibition level was determined using RT-qPCR. Data are expressed as the fold change relative to WT cells $(n=3)$. (D) The effect of miR-106a inhibition on cell proliferation was determined by CyQaunt assay. Data are expressed as relative fold change compared with day 0. Data are shown as mean \pm standard error. ${ }^{*} \mathrm{P}<0.05$ vs. WT $(\mathrm{n}=3) ;{ }^{* *} \mathrm{P}<0.05$ vs. Scrambled control $(\mathrm{n}=3)$. RT-qPCR, reverse transcription-quantitative polymerase chain reaction; VC, vector control; WT, wild type; miR, microRNA.

A

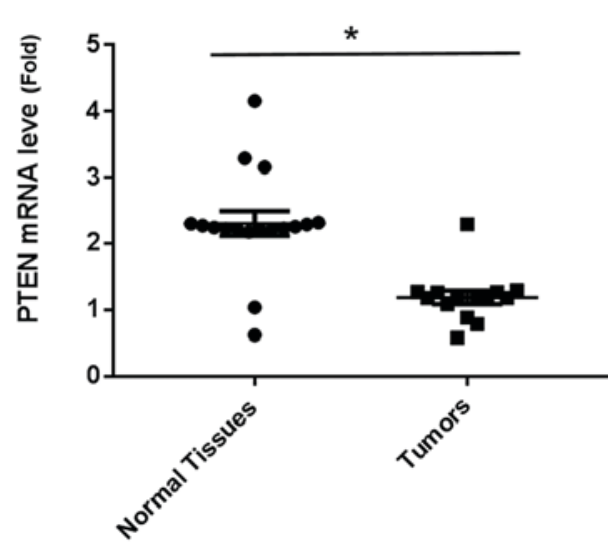

B

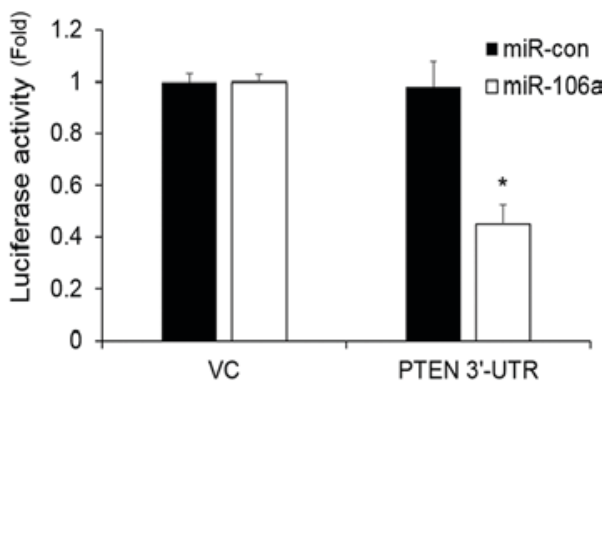

Figure 3. PTEN was repressed by miR-106a (A) PTEN mRNA levels were determined by reverse transcription quantitative polymerase chain reaction analysis in tissue samples. "P<0.05 vs. Normal tissues; (B) PC-3 cells were co-transfected with PTEN 3'-UTR or VC with miR-106a or miR-con. The result was expressed as a ratio of a given condition to $\mathrm{VC}+$ miR-con. Data are shown as mean \pm standard error, ${ }^{*} \mathrm{P}<0.05$ vs. miR-con $(\mathrm{n}=3)$. $\mathrm{PTEN}$, phosphate and tensin homolog; VC, vector control; 3'-UTR, 3'-untranslated region; con, control; miR, microRNA.
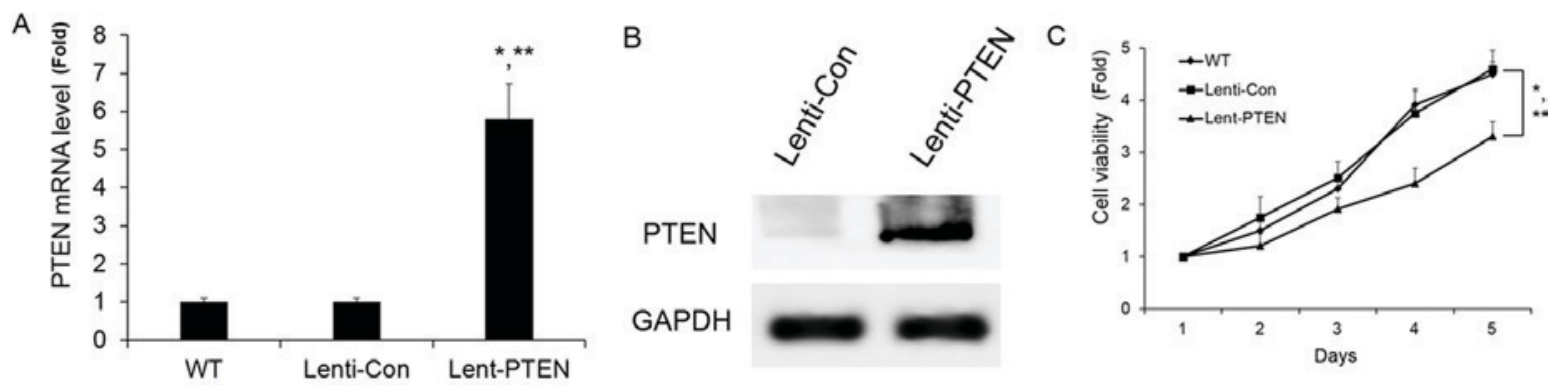

Figure 4. Effect of PTEN overexpression on cell proliferation of PC-3 cells. (A) Reverse transcription quantitative polymerase chain reaction and (B) Western blot analysis were employed to analyze PTEN mRNA and protein levels following overexpression of PTEN. GAPDH was used as a loading control. "P $<0.05$ vs. lenti-con ( $\mathrm{n}=3$ ). (C) Cell proliferation of PC-3 cells was determined following the overexpression of PTEN. Data are expressed as relative fold change compared with day 0 . Data are shown as mean $\pm \mathrm{SE},{ }^{*} \mathrm{P}<0.05$ vs. $\mathrm{WT}$; ${ }^{* *} \mathrm{P}<0.05$ vs. lenti-con $(\mathrm{n}=3)$. PTEN, phosphate and tensin homolog; WT, wild type; con, control. 
protein expression of PTEN (Fig. 4A and B). The overexpression of PTEN was observed to significantly repress PC-3 cell growth, which was consistent with the effects of miR-106a inhibition (Fig. 4C). This data suggests that miR-106a regulates prostate carcinoma progression through the involvement of PTEN.

\section{Discussion}

The expression and roles of miRNAs are tissue and cell specific. Dysregulated expression of miRNAs is a well-recognized feature of cancer. The expression and functions of miRNAs in the progression of prostate carcinoma are not fully characterized or completely understood. In the present study, miR-106a was observed to be significantly upregulated in prostate cancer tissues. Furthermore, increased expression of miR-106a significantly enhanced PC-3 cell proliferation, and loss of miR-106a repressed PC-3 cell proliferation. In addition, the present study also identified that PTEN miRNA and protein levels are negatively associated with miR-106a expression. Furthermore, PTEN overexpression significantly suppressed PC-3 cell growth in vitro. Therefore, these data suggested that miR-106a contributes to the prostate carcinoma progression with PTEN involvement and miR-106a may be a promising biological biomarker for prostate carcinoma.

miRNAs have previously exhibited promising results as potential circulating biomarkers in prostate cancer (4). miR-125 has been identified to interact with the apoptotic signaling pathway in prostate cells by targeting P53, P21 and Puma (21). miR-21 has been demonstrated to stimulate apoptosis through the P53 pathway via targeting programmed cell death 4 and PTEN (22,23). Furthermore, downregulated miR-221 enhanced the androgen-independent tumor growth and triggered a more aggressive prostate cancer phenotype (24). miR-106a has been demonstrated to serve an oncogenic role in pancreatic cancer (25). miR-106a was also identified to be upregulated in the prostate cancer group $(4,10)$. In the present study, miR-106a expression was identified to be upregulated in prostate tumor and that an increased miR-106a level was associated with the promotion of PC-3 cell growth.

PTEN is well established as a key positive and negative regulator, and as a mediator of cell growth, survival and proliferation. Additionally, PTEN is one of the most frequently disrupted tumor suppressors in cancer (26-30). Loss of PTEN cooperates with aberrant ETS transcription factor expression to promote cancer progression in the prostate (31). Furthermore, PTEN has been demonstrated as a prognostic marker for patients with non-small cell lung cancer (32). However, the association of PTEN and miR-106a remains unclear in prostate carcinoma progression. In the present study, PTEN expression was demonstrated to be decreased in prostate tumor samples. Additionally, PTEN mRNA and protein expression were increased following stable overexpression by lentiviral transfection. Furthermore, PTEN overexpression repressed PC-3 cell growth, similar to the effects observed following miR-106a inhibition. However, the data was derived from a small patient cohort. The present study generated a hypothesis that miR-106a promotes prostate cancer cell growth through regulating PTEN; however, further validation with larger datasets is necessary.
In conclusion, the present study has demonstrated that miR-106a regulates prostate carcinoma progression with PTEN involvement. The effects of miR-106a on cell proliferation may unveil its contribution to prostate cancer development, and as a result, miR-106a may be used as a potential therapeutic target for prostate cancer.

\section{Acknowledgements}

Not applicable.

\section{Funding}

This work is partly supported by National Natural Science Foundation of China (grant no. 31501052), Bethune Program of Jilin University (grant no. 2015338) and Science and Technology Development Program of Jilin Province (grant no. 20160520163JH).

\section{Availability of data and materials}

The datasets used and/or analyzed during the current study are available from the corresponding author on reasonable request.

\section{Author's contributions}

KH designed the experiments. JL performed the experiments. XM and QY derived the models and analyzed the data. All authors contributed to the final version of the manuscript.

\section{Ethics approval and consent to participate}

Written informed consent was acquired from all patients, and ethical approval was obtained from Institutional Review Board of The First Hospital of Jilin University (Changchun, China).

\section{Consent for publication}

Informed consent was obtained from all patients for publication.

\section{Competing interests}

The authors declare that they have no competing interests.

\section{References}

1. Barry Delongchamps N: Prostate cancer: Review in 2014. Diagn Interv Imaging 95: 739-742, 2014.

2. Lesko LJ and Atkinson AJ Jr: Use of biomarkers and surrogate endpoints in drug development and regulatory decision making: Criteria, validation, strategies. Annu Rev Pharmacol Toxicol 41: 347-366, 2001

3. Madu CO and Lu Y: Novel diagnostic biomarkers for prostate cancer. J Cancer 1: 150-177, 2010.

4. Jackson BL, Grabowska A and Ratan HL: MicroRNA in prostate cancer: Functional importance and potential as circulating biomarkers. BMC Cancer 14: 930, 2014.

5. Coppola V, De Maria R and Bonci D: MicroRNAs and prostate cancer. Endocr Relat Cancer 17: F1-F17, 2010.

6. Tay Y,Zhang J, Thomson AM, Lim B and Rigoutsos I: MicroRNAs to Nanog, Oct 4 and Sox 2 coding regions modulate embryonic stem cell differentiation. Nature 455: 1124-1128, 2008.

7. Calin GA and Croce CM: MicroRNA signatures in human cancers. Nat Rev Cancer 6: 857-866, 2006. 
8. Ahmad J, Hasnain SE, Siddiqui MA, Ahamed M, Musarrat J and Al-Khedhairy AA: MicroRNA in carcinogenesis \& cancer diagnostics: a new paradigm. Indian J Med Res 137: 680-694, 2013.

9. Li Y, Sun Z, Liu B, Shan Y, Zhao L and Jia L: Tumor-suppressive miR-26a and miR-26b inhibit cell aggressiveness by regulating FUT4 in colorectal cancer. Cell Death Dis 8: e2892, 2017.

10. Volinia S, Calin GA, Liu CG, Ambs S, Cimmino A, Petrocca F, Visone R, Iorio M, Roldo C, Ferracin M, et al: A microRNA expression signature of human solid tumors defines cancer gene targets. Proc Natl Acad Sci USA 103: 2257-2261, 2006.

11. Li J, Yen C, Liaw D, Podsypanina K, Bose S, Wang SI, Puc J, Miliaresis C, Rodgers L, McCombie R, et al: PTEN, a putative protein tyrosine phosphatase gene mutated in human brain, breast, and prostate cancer. Science 275: 1943-1947, 1997.

12. Steck PA, Pershouse MA, Jasser SA, Yung WK, Lin H, Ligon AH, Langford LA, Baumgard ML, Hattier T, Davis T, et al: Identification of a candidate tumour suppressor gene, MMAC1, at chromosome 10q23.3 that is mutated in multiple advanced cancers. Nat Genet 15: 356-362, 1997.

13. Miao Y, Zheng W, Li N, Su Z, Zhao L, Zhou H and Jia L: MicroRNA-130b targets PTEN to mediate drug resistance and proliferation of breast cancer cells via the PI3K/Akt signaling pathway. Sci Rep 7: 41942, 2017.

14. Liu ZL, Wang H, Liu J and Wang ZX: MicroRNA-21 (miR-21) expression promotes growth, metastasis, and chemo- or radioresistance in non-small cell lung cancer cells by targeting PTEN Mol Cell Biochem 372: 35-45, 2013

15. Wu W, Yang J, Feng X, Wang H, Ye S, Yang P, Tan W, Wei G and Zhou Y: MicroRNA-32 (miR-32) regulates phosphatase and tensin homologue (PTEN) expression and promotes growth, migration, and invasion in colorectal carcinoma cells. Mol Cancer 12: 30, 2013.

16. Alimirah F, Chen J, Basrawala Z, Xin H and Choubey D: DU-145 and PC-3 human prostate cancer cell lines express androgen receptor: Implications for the androgen receptor functions and regulation. FEBS Lett 580: 2294-2300, 2006.

17. Livak KJ and Schmittgen TD: Analysis of relative gene expression data using real-time quantitative PCR and the 2(-Delta Delta C(T)) method. Methods 25: 402-408, 2001

18. Reid G, Pel ME, Kirschner MB, Cheng YY, Mugridge N, Weiss J, Williams M, Wright C, Edelman JJ, Vallely MP, et al: Restoring expression of miR-16: a novel approach to therapy for malignant pleural mesothelioma. Ann Oncol 24: 3128-3135, 2013.

19. Thomson DW, Bracken CP, Szubert JM and Goodall GJ: On measuring miRNAs after transient transfection of mimics or antisense inhibitors. PLoS One 8: e55214, 2013.

20. Xie X, Liu HT, Mei J, Ding FB, Xiao HB, Hu FQ, Hu R and Wang MS: miR-106a promotes growth and metastasis of non-small cell lung cancer by targeting PTEN. Int J Clin Exp Pathol 8: 3827-3834, 2015.
21. Amir S, Ma AH, Shi XB, Xue L, Kung HJ and Devere White RW: Oncomir miR-125b suppresses p14(ARF) to modulate $\mathrm{p} 53$-dependent and $\mathrm{p} 53$-independent apoptosis in prostate cancer. PLoS One 8: e61064, 2013.

22. Lu Z, Liu M, Stribinskis V, Klinge CM, Ramos KS, Colburn NH and Li Y: MicroRNA-21 promotes cell transformation by targeting the programmed cell death 4 gene. Oncogene 27: 4373-4379, 2008.

23. Yang CH, Yue J, Fan M and Pfeffer LM: IFN induces miR-21 through a signal transducer and activator of transcription 3 -dependent pathway as a suppressive negative feedback on IFN-induced apoptosis. Cancer Res 70: 8108-8116, 2010.

24. Spahn M, Kneitz S, Scholz CJ, Stenger N, Rüdiger T, Ströbel P, Riedmiller H and Kneitz B: Expression of microRNA-221 is progressively reduced in aggressive prostate cancer and metastasis and predicts clinical recurrence. Int J Cancer 127: 394-403, 2010.

25. Li P, Xu Q, Zhang D, Li X, Han L, Lei J, Duan W, Ma Q, Wu Z and Wang Z: Upregulated miR-106a plays an oncogenic role in pancreatic cancer. FEBS Lett 588: 705-712, 2014.

26. Li X, Lin G, Wu B, Zhou X and Zhou K: Overexpression of PTEN induces cell growth arrest and apoptosis in human breast cancer ZR-75-1 cells. Acta Biochim Biophys Sin (Shanghai) 39: 745-750, 2007.

27. Qin Y, Huo Z, Song X, Chen X, Tian X and Wang X: mir-106a regulates cell proliferation and apoptosis of colon cancer cells through targeting the PTEN/PI3K/AKT signaling pathway. Oncol Lett 15: 3197-3201, 2018.

28. Yu YX, Wang Y and Liu H: Overexpression of PTEN suppresses non-small-cell lung carcinoma metastasis through inhibition of integrin alphaVbeta6 signaling. Am J Transl Res 9: 3304-3314, 2017.

29. de la Rosa J, Weber J, Rad R, Bradley A and Cadinanos J: Disentangling PTEN-cooperating tumor suppressor gene networks in cancer. Mol Cell Oncol 4: e1325550, 2017.

30. Li S, Shen Y, Wang M, Yang J, Lv M, Li P, Chen Z and Yang J: Loss of PTEN expression in breast cancer: Association with clinicopathological characteristics and prognosis. Oncotarget 8: 32043-32054, 2017.

31. Carver BS, Tran J, Gopalan A, Chen Z, Shaikh S, Carracedo A, Alimonti A, Nardella C, Varmeh S, Scardino PT, et al: Aberrant ERG expression cooperates with loss of PTEN to promote cancer progression in the prostate. Nat Genet 41: 619-624, 2009.

32. Xiao J, Hu CP, He BX, Chen X, Lu XX, Xie MX, Li W, He SY, You SJ and Chen Q: PTEN expression is a prognostic marker for patients with non-small cell lung cancer: A systematic review and meta-analysis of the literature. Oncotarget 7: 57832-57840, 2016. 